\title{
Por uma Sociologia da Institucionalização
} LAGROYE, Jacques; OFFERLÉ, Michel. (Orgs.) Sociologie de l'institution. Paris: Belin, 2011, 399 p.

\section{Resumo}

Jacques Lagroye e Michel Offerlé organizaram um trabalho coletivo que atualiza a agenda de pesquisas nos marcos de uma sociologie de l'institution. As reflexões apresentadas nos capítulos da coletânea, que portam sobre diferentes objetos e universos empíricos, apontam para a adoção de um olhar processual, construtivista e disposicional sobre o fenômeno institucional. Deste modo, aquilo que geralmente é concebido como consensual e inelutável, passa a ser pensado a partir de fatores históricos e sociais que interferem na sua objetivação e constante redefinição, avançando na formulação de um instrumental analítico com potente valor heurístico.

Palavras-chave: Instituição. Institucionalização. Sociologia política. Jacques Lagroye. Michel Offerlé.

\section{For a sociology of institutionalization}

\section{Abstract}

Jacques Lagroye and Michel Offerlé organized a collective publication that updates the research agenda within the frameworks of a sociologie de l'institution.

*Doutor em Ciências Sociais e em Ciência Política, Professor do Programa de Pós-graduação em Ciências Sociais e do Departamento de Sociologia e Antropologia da Universidade Federal do Maranhão (Brasil). E-mail: igorgrill@terra.com.br 
The thoughts presented in the chapters of the book covering different objects and empirical universes point out to the adoption of a procedural, constructivist and dispositional look upon the institutional phenomenon. Thus, that what is usually conceived as consensual and inevitable, here is thought from a perspective that historical and social factors interfere on its objectivation and constant redefinition, advancing in the formulation of an analytical tool with powerful heuristic value.

Keywords: Institution. Institutionalization. Political sociology. Jacques Lagroye. Michel Offerlé.

\section{Por uma Sociologia da Institucionalização}

Émile Durkheim já definira, nas Regras do Método Sociológico, a sociologia como a ciência das instituições, de suas gêneses e de seus funcionamentos. Marcel Mauss, por sua vez, fixou o uso de uma concepção alargada de instituição e a utilização do termo para práticas, usos e valores relativos às sociedades com diferentes graus e modalidades de codificação de regras, englobando desde superstições até organizações jurídicas, passando por constituições políticas. Desde então, ao menos na França, os sociólogos têm uma forte atração pela apreensão daquilo que é "instituído" socialmente.

A partir dos anos 1980, parte dos expoentes da sociologia política francesa procedeu a uma ruptura com a tradição jurídica no que diz respeito a objetos relativamente caros à ciência política de um modo geral, apostando na ênfase em uma perspectiva processual, construtivista e disposicional de análise. Os usuários do instrumental em pauta foram significativamente influenciados pelos trabalhos de Pierre Bourdieu e Luc Boltanski (deste último, principalmente Les Cadres, de 1982) e também pela sociologia histórica de Norbert Elias e Charles Tilly (entre outros).

Os estudos desenvolvidos têm orbitado em torno de uma agenda de pesquisas sistematizada por Bernard Lacroix e Jacques Lagroye em dois textos 
seminais: a Ordre politique et ordre social: objetivisme, objetivation et analyse politique (publicado por Lacroix no Traité de Science Politique, organizado por Madeleine Grawitz e Jean Leca em 1985) e a introdução (assinada pelos dois autores que são igualmente organizadores) do livro Le Président de la République: usages e genèses d'une institution (lançado em 1992).

A construção permanente do instituído e os investimentos constantes, responsáveis pela objetivação das instituições, entram na ordem do dia. De forma sintética, ganham relevo no programa de investigações a atuação de agentes pensados como empreendedores em espaços concorrenciais, os mecanismos de institucionalização e os dispositivos de inculcação de normas, valores, crenças, papéis, práticas tidas como legítimas, e rotinizadas, socializadas, codificadas, propagadas, disputadas e subvertidas em domínios diversos.

A coletânea ora resenhada é intitulada Sociologie de l'institution e foi dirigida por Jacques Lagroye e Michel Offerlé, dois protagonistas no empenho de redefinição da ciência política francesa sob as bases teóricas em questão. Para além da atualização do debate, a discussão proposta avança na interlocução e, particularmente, na consigna de diferenciações com vertentes do que veio a ser denominado de neoinstitucionalismo nas últimas décadas. Os organizadores acentuam, na introdução do livro, que se trata de um trabalho coletivo, reunindo pesquisadores de diferentes gerações que compartilham de um mesmo imperativo teórico e metodológico, qual seja o de considerar indissociavelmente o caráter coercitivo das instituições e o quanto elas devem aos investimentos (conscientes ou não) dos agentes, no sentido da sua invenção, adaptação, consolidação, reforma, reprodução, insubordinação, etc.

Conjuga-se a isso a reivindicação do alcance heurístico de se privilegiar o tratamento de diversos domínios sociais e objetos por meio de conceitos e métodos comuns, assim como sua pertinência vis-à-vis às 
abordagens em termos de campos, empresas, organizações, redes, etc. O ângulo do olhar adotado aparece elaborado na introdução e no capítulo 12 da obra, que reproduz um debate entre Jacques Lagroye, Michel Offerlé, Vicent Dubois, Jean-Michel Eymeri-Douzans, Bastien François e Olivier Nay. Neste momento, vêm à tona implicações no que diz respeito às compatibilidades e correlações entre noções (como as de habitus e papéis), às bases e às apropriações de diferentes tradições sociológicas mobilizadas (bourdiesiana, foucoultiana, giddesiana, goffmaniana...), assim como às distinções de enfoque decorrentes das condições de formulação de indagações acerca das instituições nos Estados Unidos da América.

A propósito, Nicolas Freymond (capítulo 1) explora as variações nacionais da chamada redescoberta das instituições pela sociologia. Ele observa que nos EUA isso é resultante da crítica ao contextualismo ou às explicações por fatores exógenos (traduzidos como recursos de elite para as denominadas teorias elitistas, como cultura política para as behavioristas ou como preferências satisfeitas de maneira ótima para as teorias da escolha racional), ao passo que, na Europa, o deslocamento estaria fundado nos afastamentos das análises jurídicas e do marxismo associado às figuras de Poulantzas e Miliband.

A obra está dividida em quatro partes. Alinhavando uma sequência lógica, são problematizados aspectos da Ordem Institucional (Parte 1); das dinâmicas, dos condicionantes e das práticas que contribuem para Produzir a Instituição (Parte 2); dos alinhamentos que plasmam tais instituições (consensos e culturas) e estabelecem A Força do Instituído (Parte 3); da constituição de habitus, papéis, propriedades e fidelidades que vinculam os agentes às instituições ou que lhes permitem Ter seu papel institucional (Parte 4). Os referidos fatores responsáveis pelo processo de institucionalização são relacionados a uma gama de temas que delineiam o campo da sociologia política francesa. 
Cabe ressaltar, então, o potencial explicativo desse ponto de vista demonstrado à luz do exame de: reformas institucionais nos terrenos constitucionais, eleitorais, judiciário, administrativo, etc. (Philippe Bezes e Patrick Le Lidec); criação de ministérios (Julien Meimon); instituições voltadas para o atendimento de imigrantes (Choukri Hmed e Sylvain Laurens); regimes de cooperação entre cidades (Fabien Desage e Bastian Sibille); lógicas de realização de concursos públicos (Émile Biland); engajamentos em instituições partidárias (Julien Fretel); ingresso de novos personagens no cenário público, tal como a chegada de socialistas em espaços eletivos (Rémi Lefebvre) e de mulheres nos campos jurídico e político (Delphine Dulong); assim como a ação do militantismo institucional em uma ordem dominicana (Yann Raison du Cleuziou).

O alargamento do leque de preocupações analíticas, a partir do horizonte construtivista, se observa na primazia direcionada à invenção/reinvenção de instituições pelo trabalho político dos agentes. Notadamente, podem ser destacados três conjuntos de elementos privilegiados nas pesquisas. No primeiro, grifa-se a gênese das reformas institucionais; a afirmação dos empreendedores reformadores; a resistência de beneficiários diretos e indiretos dos arranjos pré-existentes; as fontes de mutações (tais como as transformações macro-sociais); as dinâmicas endógenas às organizações; modos e lógicas da redistribuição de poder e recursos entre atores em domínios diferenciados; a fabricação de um senso comum reformador; o entabulamento de coalizões de reformadores; as negociações; a produção de novos significados; são alguns dos pontos descritos por Philippe Bezes e Patrick Le Lidec (capítulos 2 e 3). No segundo, tem-se a sequência inicial da institucionalização; os discursos que as apresentam como acontecimentos lógicos e legítimos; os conflitos e tensões com setores burocráticos concorrentes pela materialização e pelo reconhecimento social e político; entre outros traços ressaltados por Julien Meimon (capí- 
tulo 4). E, no terceiro, sublinham-se os movimentos individuais e coletivos de resistência aos processos de institucionalização, evidenciando o quanto, na trilha de autores como Charles Suaud e Louis Pinto, as resistências aparentes se devem a transformações morfológicas mais amplas do espaço social, a socializações anteriores e a adaptações secundárias (tais como definidas por Goffman). Sendo possível, então, questionar de que forma colaboram para a produção de determinada instituição e como permitem detectar suas lógicas de funcionamento, exemplarmente caracterizadas por Choukri Hmed e Sylvain Laurens (capítulo 5).

De mesma ordem, a força do instituído se evidencia na imposição de uma feição consensual e eterna. Todavia, como postulam Fabien Desage e Bastian Sibille (capítulo 6), esta aparência de inelutável é resultado de formalizações, de mobilizações de atores sociais, de prescrições ortodoxas e heterodoxas (os chamados conflitos de interpretações), sendo que a imagem de um campo de forças em tensão parece mais apropriada que aquela de objetos rígidos para figurar o exercício da coação institucional (p. 175). Esta amplitude do emprego da noção de instituição autoriza, de acordo com Émile Biland (capítulo 7), o uso da ideia de cultura institucional que engloba linhas complementares, a saber:

a dimensão ideal e a dimensão prática, [...] a aprendizagem e a transmissão [...], afora as apropriações individuais e coletivas. [Há ainda] as condições de consolidação e transformação no tempo. [E] os conflitos pela definição das formas de pensar e de agir [como sendo] características de uma instituição. (p. 180).

Notavelmente, a análise de percursos individuais e suas imbricações com o modus operandi em um domínio específico funciona como instrumento heurístico para a reflexão centrada nos ajustamentos entre disposições e regras/papéis prescritos. Isto é, tal expediente torna-se imprescindível, seguindo o raciocínio de Julien Fretel (capítulo 8), para a 
compreensão das pulsões vertidas nos investimentos concretos dos agentes, transcritas nos seus engajamentos, vislumbrando modelar e modificar as próprias regras, e ainda refletidas (ou refletindo) na incorporação de saberes, crenças e modalidades legítimas de agir.

Com efeito, a instituição, no sentido amplo assumido na obra, segundo Remi Lefebvre (capítulo 9), designa um conjunto de comportamentos, de atitudes e de discursos, em síntese: de papéis sociais que estão submetidos a maneiras de fazer e de dizer cristalizadas e mais ou menos estabilizadas que Ihe estão associadas (p. 220). Como resultado, os papéis políticos desempenhados por titulares de cargos políticos se impõem aos mesmos porque se configuram a um só tempo como modelos de ação e recursos e como coações (p. 221). Ocorre que, esses condicionantes somente podem ser apurados em estudos que se dedicam à apreensão dos trajetos individuais e que atentam para os mecanismos de aprendizagem e para as sequências de incorporação de papéis. Adicionase a isso a necessidade de se levar em conta tanto as situações mais codificadas, públicas e oficiais (o exercício de algumas funções parlamentares, por exemplo), quanto as mais fluidas, de tipo face a face e pessoalizadas (observáveis no chamado corpo a corpo eleitoral, apenas para citar uma modalidade de atividade política conhecida).

A despeito dos diferentes mecanismos de objetivação ou institucionalização que podem estar em tela, é possível perceber - partilhando uma sociologia disposicional da ação política como faz Delphine Dulong (capítulo 10) - os efeitos interdependentes das propriedades dos protagonistas, das instituições e das situações. Por conseguinte, numa primeira direção, cumpre identificar os protagonistas mais ou menos autorizados ou "capacitados" a conduzir ou subverter instituições, tendo em vista as suas posições objetivas em dado espaço de relações competitivas e/ou cooperativas. Numa segunda direção, é indubitavelmente pertinente verificar os dispositivos de controle, internos às instituições, relativamente 
codificados e o peso que exercem sobre o ingresso e a carreira dos agentes em um âmbito especializado. Desenham-se lógicas interseccionadas e passíveis de serem reveladas em contextos específicos e por meio de acompanhamento/observação de práticas in loco e nos seus bastidores.

Esforço nesta direção foi feito por Yann Raison Du Cleuziou (capítulo 11), debruçando-se sobre os militantismos institucionais e procurando depreender os mecanismos de identificação institucional. A questão para ele reside na necessidade de superar o dualismo ator versus instituição, implícita ou explicitamente presente na tipologia cunhada por Albert Hirschman para a compreensão das iniciativas dos indivíduos insatisfeitos em circunstâncias de deterioro de uma organização ou firma. É preciso extrapolar a aplicação das categorias saída, voz e lealdade, atendo-se à fidelidade paradoxal que se manifesta na ruptura que faz, por sua vez, emergir o repertório do militantismo em conjunturas críticas (p. 269-270). Por esse intermédio, é possível contemplar como nesses momentos os posicionamentos são marcados por fidelidades concorrentes, transladadas ou sintetizadas em repertórios de ação que vão da conformação ao desengajamento, passando pelo protesto interno ou externo à instituição.

Para finalizar, algumas notas sobre a relevância do enfoque proposto pelos autores da coletânea organizada por Lagroye e Offerlé, nos contornos das ciências sociais no Brasil, sobretudo para a ciência política, que, acredita-se, poderiam enriquecer-se com os esquemas analíticos construídos pela sociologia política francesa dos últimos trinta anos. Para algumas indicações neste sentido, podem ser citadas três problemáticas em voga que vêm ocupando as referências brasileiras, especialmente no que diz respeito às análises politológicas: reforma política, instituições e democracia e instituições e participação política.

Em tempos de acaloradas polêmicas em torno das chamadas "reformas", entre elas a "reforma política", com constantes tomadas de posição de personagens do mundo acadêmico, constata-se, por um lado, uma 
intrincada dinâmica de empreendedores da reforma e de gestão de um senso comum reformador. Por outro lado, elevam-se resistências e obstáculos, alianças insólitas e prescrições concorrentes sobre uma problemática que se impõe como legítima.

Analogamente, o recorrente debate sobre as bases institucionais da democracia brasileira (entre elas os partidos políticos) pode ser deslocado do terreno normativo, seguindo as orientações aqui expostas (de um viés processual, construtivista e disposicional) que viabilizam a compreensão de dinâmicas de objetivação ou de institucionalização (e as regras formais e informais que comportam). Isso em detrimento das meras e ambivalentes avaliações sobre o bom ou mau funcionamento das instituições ou das possíveis medidas para melhorá-las, geralmente condizentes com as batalhas temporais por conquista ou preservação de posições no espaço do poder, o que incide na persistente vulnerabilidade das fronteiras que poderiam garantir alguma autonomia no trabalho acadêmico.

$\mathrm{E}$, no que tange aos mecanismos de atuação em universos diversos (movimentos sociais, organizações não governamentais, sindicatos, partidos, burocracia, etc.), esses podem ser iluminados mediante a ponderação das convergências entre disposições e papéis prescritos a agentes situados em domínios com regras heterogêneas e em posições hierárquicas variadas. Possibilitando ainda aos pesquisadores captar os repertórios (individuais e coletivos) ativados, os recursos, as competências, as tecnologias aplicados na constituição de "grupos" ou "coletividades", de porta-vozes e de aderentes, bem como os investimentos múltiplos que realizam na instituição em seus diferentes estágios (formação, renovação, crise, redefinição, etc.). Por conseguinte, revelando, nas investigações desses processos, os condicionantes e as condições sociais e históricas responsáveis por identificações, engajamentos, fidelidades, clivagens, deserções e dissidências. 